\title{
Development and Validation of Strategic Intervention Materials (SIMs) of the Selected Topics in Trigonometry of Precalculus Discipline in Senior High School
}

\author{
Jay Fie P. Luzano \\ PhD Student, University of Science and Technology of Southern Philippines, Cagayan de Oro City, Philippines \\ Faculty, College of Education, Bukidnon State University, Malaybalay City, Bukidnon, Philippines \\ Corresponding Author: Jay Fie P. Luzano, E-mail: jayfieluzano@gmail.com
}

\begin{tabular}{|c|c|}
\hline ARTICLE INFORMATION & ABSTRACT \\
\hline $\begin{array}{l}\text { Received: October 15, } 2020 \\
\text { Accepted: December 05, } 2020 \\
\text { Volume: } 1 \\
\text { Issue: } 2\end{array}$ & $\begin{array}{l}\text { Shaped with Vygotsky's Principle on Scaffolding, this study aimed to develop and } \\
\text { validate learning materials known as Strategic Intervention Materials (SIMs) of the } \\
\text { selected topics in Trigonometry in the STEM strand. This developmental study } \\
\text { undertook three phases, namely: planning, development, and validation and guided } \\
\text { by the ADDIE Model in the data analysis. In the planning stage, the least-mastered }\end{array}$ \\
\hline $\begin{array}{l}\text { Development, least-mastered } \\
\text { competencies, Strategic } \\
\text { Intervention Materials, validation, } \\
\text { validators, Trigonometry, Pre- } \\
\text { Calculus }\end{array}$ & $\begin{array}{l}\text { competencies (LMC) were selected based on the results of their final examination in } \\
\text { Pre-Calculus in the field of Trigonometry. The researcher made two SIMs based on } \\
\text { the identified (LMC). The second stage is the development of the materials that } \\
\text { were presented and critiqued by the thesis adviser, students, colleagues, and SIM } \\
\text { experts. In the last stage, the content and student validators validated the } \\
\text { developed learning materials. The validators were purposively chosen. The adapted } \\
\text { instrument was used in validating the materials. The developed SIMs were rated } \\
\text { "excellent" by the content-validators and "more than adequate" by the student- } \\
\text { validators. This implied that the content-validators considered the SIMs as teacher } \\
\text { support materials that can be used to master the competencies in Pre-Calculus and } \\
\text { learner enhancers to improve their competence as evaluated by the student- } \\
\text { validators. The validation results of the two SIMs paved the way for the } \\
\text { construction of the new learning material to confirm the findings and undergone } \\
\text { validation were rated "excellent" and "more than adequate" by content and } \\
\text { student validators respectively. It is recommended that teachers should develop } \\
\text { more SIMs for other disciplines to address students' difficulties in learning } \\
\text { Trigonometry. }\end{array}$ \\
\hline
\end{tabular}

\section{Introduction}

In the dynamic 21st-century education landscape, the Philippine academic system is in the quest for seeking new and innovative ways to reach out the diverse learners. In this globally competitive world, education plays a significant role in every individual's life. Through education pieces of training and interventions, a learner is equipped with the necessary knowledge, attitude, and skills needed for life-long learning (Bryant, 2006).

The interplay in the spiral approach in the Mathematics curriculum upon the implementation of the K to 12 programs became the challenge in teaching Trigonometry and problems are exceedingly experienced. In the study of Javier (2013), after a year on the Implementation of Spiral Approach in teaching Mathematics, it was discovered that with the four areas such as Learners' Competency, Teaching Competency, Assessment Tools and Instructional Materials, the least managed of them all is the Learners' Competency.

K C AL-KINDI CENTER

R D FOR RESEARCH AND DEVELOPMENT Your gateway to world-class research
Published by Al-KindiCenter for Research and Development. Copyright (c) the author(s). This is an open access article under CC BY license (https://creativecommons.org/licenses/by/4.0/) 
The learners are the center of the educative process. Since the implementation of the $\mathrm{K}$ to 12 for high school is sudden, the students experienced a learning gap for each subject area. As to this matter, learning Mathematics is one of the obstacles particularly in the field of trigonometry. Mathematics, as a highly complicated and sophisticated yet practical discipline, empowers a person with opportunities to develop life and practical skills. Learning the mathematical terms philosophically is an essential part of becoming a liberally educated person, however, this subject has always been viewed as the most difficult and misunderstood subject (Lewis, 2013).

Trigonometry, as a mathematical discipline, is believed to be particularly abstract and difficult compared with the other subjects of mathematics. It is governed by concepts that only a few learners perform and succeed at, and which most students struggle and sacrifice with. Trigonometry is generally taught in the secondary with most books conventionally starting with naming sides of right triangles (Gur, 2009).

Orhun (2015) found out that many learners faced challenges and complexities in using trigonometry for solving problems. He identified that students were not able to develop skills on the concepts of trigonometry certainly resulted in committing some mistakes. Consequently, learners made many errors due to the rule on mechanical application in trigonometry exercises. These errors occur because Mathematics is categorized as hierarchical where learning processes must be technically interrelated and procedural.

Different studies have identified students and teachers experiencing difficulty in formulating a meaningful and synchronized understanding of trigonometry. Furthermore, research has exposed that students have a problem in reasoning about topics foundational to trigonometry, such as solving right and oblique triangles. The findings of the study conjectured that the foundational understandings of this subject area are necessary to construct valuable and meaningful techniques in solving problems connected to the aforementioned subject (Markel, 2000).

Deficiency of educational facilities and instructional materials, large class size, poor instruction, and non-differentiated instructional methodologies and curriculum are problems that threaten the education process. The present academic system of the country is filled with controversies in terms of classroom shortage and scarce funding to provide for instructional materials required in each Mathematics classroom. These issues disrupt the teaching and learning process to grow and explore. In these predicaments, the teaching process is hindered and, in turn, achievement in learning is not realistic. Lots of students had weak coping mechanisms with these problems that result in their poor performance. The ultimate goal of teaching is to provide appropriate and practical instruction to students and, in turn, promoting active and effective learning. Thus, teachers, themselves, become agents in combating these predicaments to achieve a successful education process by devising and providing necessary materials that are suitable to students' needs (Weselby, 2014).

The teacher's initiative in crafting and utilizing instructional materials bridges the learning gaps towards the achievement of the educational goals, learning the concepts, and mastering the skills. The productivity of teaching trigonometry is enhanced upon having available, sufficient, and strategically designed instructional and intervention materials appropriate for different students, considering their learning styles, personality types, and stress-coping mechanisms. Hence, it is imperative that Mathematics teachers have a holistic understanding of their learners to craft personalized instructional materials, thus addressing students' individual needs to achieve better comprehension in trigonometry (Dacumos, 2015).

The role of developing instructional and intervention materials in the teaching-learning process should not be undermined. It plays an integral role in the achievement of a fruitful interplay of teaching and learning. If adequately prepared, these materials will be useful and effective in terms of enhancing, facilitating, and making teaching and learning smooth, lively, and concrete (Olawale, 2013).

The Department of Education (DepEd) had employed a solution for the deteriorating academic performance of students in the field of Mathematics. As stipulated in the DepEd Order No. 39, series of 2012, interventions have to be made to address learning gaps. The use of Strategic Intervention Material (SIM), is identified as one of the suggested various interventions that can bridge learning gaps. SIM is a remediation aid for the students at the level of their understanding and thereby increasing their academic achievement.

SIM was defined as meant to re-teach the concepts and least mastered skills, and in this study, the Mathematics concepts and skills. It is a material given to students to aid in learning and mastering the competency-based skills which they were not 
able to develop in regular classroom instructions. SIM is a multifaceted approach to assist the students, especially those who are non-performing to become independent and successful learners (Bunagan, 2012).

Assessments in SIM include a variety of techniques that allow students to demonstrate evidence of learning such as performance of tasks and applying to real-life situations. Strategic Intervention Materials (SIMs) are aimed to help teachers provide students the needed reinforcement to make progress in their respective subjects (Drucker, 2006).

Although the learners' materials are well-provided, students are still having a hard time in the topic, and it was found out in the study of Javier (2013) that the Mathematics skills and competencies that were expected of the students are not on the considerable level. In line with this, the researcher would like to develop a Strategic Intervention Material (SIM) that helps improve the students' competence in the selected topics in Pre-Calculus, particularly Trigonometry.

\section{Research Objectives}

Specifically, this study sought to answer the following queries:

1. What are the procedures followed in the development of the Strategic Intervention Materials (SIMs) of the selected topics in Trigonometry?

2. To what extent do the content and student validators validate the Strategic Intervention Materials (SIMs) based on the following criteria:

2.1. Design;

2.2. Clarity of directions used;

2.3. Readability;

2.4. Importance of the content;

2.5. Appropriateness of activities;

2.6. Ease of task completion;

2.7. Opportunities for active learning; and

2.8. Usefulness in meeting the needs of the learners?

3. What changes or improvements can be made to make the SIMs more useful to learners based on their cards:

3.1. Guide card;

3.2. Activity card;

3.3. Assessment card;

3.4. Enrichment card; and

3.5. Reference card?

4. What are the overall comments made by the content and student validators on the developed Strategic Intervention Materials (SIMs)?

5. Based on the results of the study, what SIM can be designed based on the learning competencies specified in the Curriculum Guide (CG) of Pre-Calculus?

\section{Materials and Methods}

This study was generated using developmental research design. The first part was descriptive for it selected the leastmastered competencies in Pre-Calculus, particularly in Trigonometry and developmental for it aimed to develop Strategic Intervention Materials (SIMs) as teacher support material to reinforce the poor performance of the students and validate them in terms of their content and presentation.

Calderon (2012) explained in his book entitled Methods of Research and Thesis Writing that descriptive research is a purposive process of gathering, analyzing, classifying, and tabulating data prevailing conditions, practices, beliefs, processes, trends, and cause-effect relationships and then making an adequate and accurate interpretation about such data with or without the aid of statistical methods. This method was used in determining the curricular validity of the Strategic Intervention Materials (SIMs).

The participants of this study were the twenty-five (25) content-validators who validated the content and presentation of the SIMs. They are both private and public school teachers who are Master's degree holders with a specialization in Mathematics and have been teaching in the large schools in Pagadian City. All of them are teaching Mathematics for at least three years 
and have attended various training on instructional designing and the twenty-five (25) student-validators who are STEM strand enrollees.

To determine both the numerical and descriptive equivalent of the validation of the developed Strategic Intervention Materials (SIMs), the researcher adopted an instrument made use by Nivera as cited in Saclao, 2015.

\begin{tabular}{cll}
\hline Hypothetical Mean Range & Content-Validators & $\begin{array}{c}\text { Descriptive Equivalent } \\
\text { Student-Validators }\end{array}$ \\
\hline $4.21-5.00$ & Excellent & More Than Adequate \\
$3.40-4.20$ & Above Average & Adequate \\
$2.61-3.40$ & Average & Partially Adequate \\
$1.81-2.60$ & Below Average & Inadequate \\
$1.00-1.80$ & Needs Improvement & Extremely Inadequate \\
\hline
\end{tabular}

Strategic Intervention Materials (SIMs) were developed through the guide of an instructional design model such as the ADDIE (Analysis-Design-Development-Implementation-Evaluation) model. The steps and processes were modified and customized to the nature of the learning material that was developed. Specifically, for this study the Strategic Intervention Materials (SIMs) were developed through these stages: (1) Preparation; (2) SIM Development; (3) SIM Presentation and Consultation to the thesis adviser, students, colleagues, and SIM designers; (4) SIM Validation by the content and student validators.

\section{Results and Discussion}

The study was guided by the steps of the instructional design model, specifically by the ADDIE model. ADDIE model is an instructional design method and framework in designing and developing educational learning materials which stand for Analyze, Design, Develop, Implement, and Evaluate. The model has been modified and customized for the study, and hereby composed of the following stages:

\begin{tabular}{|c|c|}
\hline Original ADDIE Model & Modified Model \\
\hline Analysis & Preparatory Stage \\
\hline Design & \\
\hline Development & SIM Development \\
\hline Implementation & $\begin{array}{l}\text { SIM Presentation and Consultation to the thesis adviser, students, } \\
\text { colleagues, and SIM experts }\end{array}$ \\
\hline Evaluation & SIM Validation by the content and student validators \\
\hline
\end{tabular}

Figure 1. Instructional Design Model of the Study

The preparatory stage includes analyzing, planning, and conceptualizing the Strategic Intervention Materials (SIMs) being developed. Grade 12 STEM students were assessed. Based on the Final examination in Pre-Calculus in Trigonometry unit given to them on the First Semester Academic Year 2018-2019, the results revealed that most of the Grade 12 STEM students 
got very low scores in the examination having a Mean Percentage Score (MPS) of 51.45 out of a 100 -item test with 248 takers.

With the aforementioned results, the researcher was able to find a cure for the said problem and selected the topics and the learning competencies that were not mastered by the students. Hence, the researcher came up with the idea of developing Strategic Intervention Materials (SIMs) to address the said learning gaps so that those students who are not yet mastered the lesson can still cope up. The preparation of materials, determination of the format to be used, and other pertinent aspects in the development of the SIM were established in this stage.

The development stage focuses on the design and development of the learning materials in which the least-mastered competencies were made as bases. The following steps were undertaken in the development of the SIM according to Saclao (2015): (1) Developing SIM rationale; (2) Deciding on aims and learning outcomes; (3) Thinking about the content; (4) Exploring learning and teaching strategies and the appropriate learner support; and (5) Planning validation strategy.

Table 1. Blueprint of the Strategic Intervention Materials (SIMs)

\begin{tabular}{clccc}
\hline Quarter & \multicolumn{1}{c}{ Preparatory Competencies } & Topics & SIM No. & Title \\
\hline 2 & $\begin{array}{l}\text { Determine the missing lengths of the sides } \\
\text { and measures of the angles of right } \\
\text { triangles. }\end{array}$ & Right Triangles & 1 & The Right Try \\
& $\begin{array}{l}\text { Determine the missing lengths of the sides } \\
\text { and measures of the angles of oblique } \\
\text { triangles. }\end{array}$ & Oblique Triangles & 2 & $\begin{array}{c}\text { The Oblique } \\
\text { Attempt }\end{array}$ \\
\hline
\end{tabular}

Figure 2. Strategic Intervention Materials (SIMs) Covers
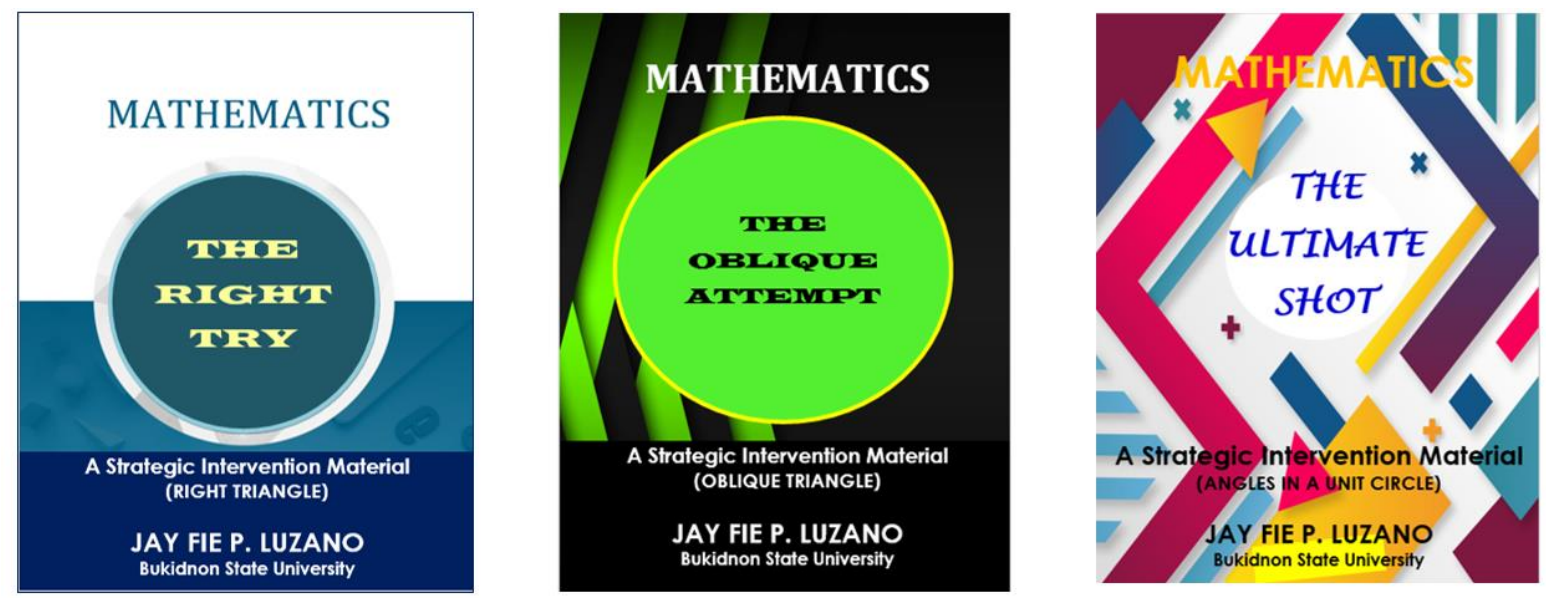

During the SIM presentation and consultation, the implementation phase of the ADDIE model was emphasized. However, in this study, the implementation phase was focused on the presentation and consultation of the learning materials to the thesis adviser, colleagues, and SIM designers. The first drafts of the SIM went through informal validation. Each developed SIM was presented and consulted to STEM students for the researcher to pre-assess each of the materials. Subsequently, they were presented to the adviser and colleagues for some corrections. After this, the insights of the SIM designers were sought to determine the strong and weak points of the developed SIMs. Comments and suggestions were considered for improvement.

In the validation stage, the validation of the content of the developed SIMs was based on: (1) design; (2) clarity of directions used; (3) readability; (4) importance of the content; (5) appropriateness of activities; (6) ease of the task completion; (7) 
opportunities for active learning; and (8) usefulness in meeting the learners' needs. Part of the validation were the comments and suggestions as to further improvements on the different parts or cards of the SIMs made by the content and student validators at the same time the final revision also has complied. As to the validation, participants were fully informed on the nature of this developmental research. Based on the validation results, the researcher was also encouraged to make a brand new Strategic Intervention Material (SIM) to fully confirm the findings of the study.

Data analysis and synthesis in a developmental study are comparable to the other research projects. There are likely to be descriptive data presentations and qualitative data analyses using data from surveys and observations. Traditional quantitative data analysis and techniques are used as well to validate well the learning materials developed (Seels and Richey, 1994).

Table 2 presents the validation of the content-validators of SIM No. 1 (The Right Try). As displayed in the table, it shows that readability surmounts among the eight criteria with a mean of 5.00, descriptively interpreted as excellent and appropriateness of activities, ease of task completion, and opportunities for active learning has the lowest mean of 4.60, but still interpreted as excellent. All of the criteria have the highest rating manifesting the overall mean response of 4.75 and interpreted as excellent. This only showed that SIM No. 1 (The Right Try) has a higher suitability level in meeting the needs of the STEM students if they can experience difficulty in their lessons about this area in Trigonometry.

Various researches purport to this result. Orhun (2002) concluded that most often learners have difficulties in understanding concepts in Mathematics particularly if the material is not well-developed. This could also one of the factors that hinder the learners' understanding of Mathematics. This problem was addressed by the result of this SIM since readability exhibits a maximum rating from the content-validators.

Table 2. Content-validators' Validation of SIM No. 1 (The Right Try)

\begin{tabular}{llcc}
\hline & \multicolumn{1}{c}{ Criteria } & Mean & Interpretation \\
\hline 1. & Design of the SIM & 4.80 & Excellent \\
2. & Clarity of directions used & 4.80 & Excellent \\
3. & Readability & 5.00 & Excellent \\
4. Importance of the content & 4.80 & Excellent \\
5. Appropriateness of activities & 4.60 & Excellent \\
6. & Ease of task completion & 4.60 & Excellent \\
7. Opportunities for active learning & 4.60 & Excellent \\
8. Usefulness of the SIM in meeting & 4.80 & Excellent \\
& $\quad$ the needs of the learner \\
$\quad$ Overall Mean & $\mathbf{4 . 7 5}$ & Excellent \\
\hline
\end{tabular}

Table 3 exhibits the validation of the content-validators of SIM No. 2 (The Oblique Attempt). As presented in the table, it shows that readability and usefulness of the SIM excel among the eight criteria with a mean of 5.00, descriptively interpreted as excellent and ease of task completion has the lowest mean of 4.40, but still interpreted as excellent. All of the criteria have the highest rating manifesting the overall mean response of 4.75 and interpreted as excellent. This only showed that SIM No. 2 (The Oblique Attempt) has a higher suitability level in meeting the needs of the STEM students same with SIM No. 1 if they can experience difficulty in their lessons about this area in Trigonometry.

Few pieces of research confirm this result. Dahar (2012) emphasized that the usefulness of instructional materials has a strong relationship with the academic performance of the students. Thus, the instructional materials play an important role in improving students' academic achievement. This SIM imparts a significant outcome towards developing an interest to the side of the students in learning Trigonometry. 
Table 3. Content-validators' Validation of SIM No. 2 (The Oblique Attempt)

\begin{tabular}{llcc}
\hline & \multicolumn{1}{c}{ Criteria } & Mean & Interpretation \\
\hline 1. & Design of the SIM & 4.80 & Excellent \\
2. & Clarity of directions used & 4.60 & Excellent \\
3. & Readability & 5.00 & Excellent \\
4. & Importance of the content & 4.80 & Excellent \\
5. Appropriateness of activities & 4.60 & Excellent \\
6. & Ease of task completion & 4.40 & Excellent \\
7. $\quad$ Opportunities for active & 4.80 & Excellent \\
& learning & & Excellent \\
8. & Usefulness of the SIM in & 5.00 & \\
& meeting the needs of the & & Excellent \\
& learner & & $\mathbf{4 . 7 5}$
\end{tabular}

Table 4 presents the validation of the student-validators of SIM No. 1 (The Right Try). As gleaned in the table, it shows that appropriateness of activities and ease of task completion top among the eight criteria with a mean of 4.80 , descriptively interpreted as more than adequate and clarity of directions has the lowest mean of 4.20 , interpreted as adequate. All of the criteria have the highest rating manifesting the overall mean response of 4.58 and interpreted as more than adequate. This only showed that SIM No. 1 (The Right Try) has the potential and more than adequate to meet the needs of the STEM students if they cannot cope up directly with their lessons about this area in Trigonometry.

Several types of research affirm the findings of this result. Cooper (2005) concluded that the self-learning material must be rooted in different viewpoints to accommodate the least mastered skills of the students so that they will be productive in discovering their learning upon certain concepts. Hence, this study stimulates their interest for they find the activities in this SIM easy.

Table 4. Student-validators' Validation of SIM No. 1 (The Right Try)

\begin{tabular}{llcc}
\hline & \multicolumn{1}{c}{ Criteria } & Mean & Interpretation \\
\hline 1. & Design of the SIM & 4.40 & More Than Adequate \\
2. & Clarity of directions used & 4.20 & Adequate \\
3. & Readability & 4.60 & More Than Adequate \\
4. & Importance of the content & 4.60 & More Than Adequate \\
5. & Appropriateness of activities & 4.80 & More Than Adequate \\
6. & Ease of task completion & 4.80 & More Than Adequate \\
7. & Opportunities for active learning & 4.60 & More Than Adequate \\
8. & Usefulness of the SIM in meeting & 4.60 & More Than Adequate \\
& your needs as a learner & & More Than Adequate \\
\hline
\end{tabular}

Table 5. Student-validators' Validation of SIM No. 2 (The Oblique Attempt)

\begin{tabular}{llcc}
\hline & \multicolumn{1}{c}{ Criteria } & Mean & Interpretation \\
\hline 1. & Design of the SIM & 4.00 & Adequate \\
2. & Clarity of directions used & 4.20 & Adequate \\
3. & Readability & 4.40 & More Than Adequate \\
4. & Importance of the content & 5.00 & More Than Adequate \\
5. & Appropriateness of activities & 4.80 & More Than Adequate \\
6. & Ease of task completion & 4.60 & More Than Adequate \\
7. & Opportunities for active learning & 4.80 & More Than Adequate
\end{tabular}




\begin{tabular}{|c|c|c|c|}
\hline 8. & $\begin{array}{l}\text { Usefulness of the SIM in meeting } \\
\text { your needs as a learner }\end{array}$ & 5.00 & More Than Adequate \\
\hline & Overall Mean & 4.60 & More Than Adequate \\
\hline
\end{tabular}

Table 5 presents the validation of the student-validators of SIM No. 2 (The Oblique Attempt). As exhibited in the table, it shows that importance of the content and usefulness of the SIM dominate among the eight criteria with a mean of 5.00, descriptively interpreted as more than adequate, and design of the SIM has the lowest mean of 4.00, interpreted as adequate. All of the criteria have the highest rating manifesting the overall mean response of 4.60 and interpreted as more than adequate. This only showed that SIM No. 2 (The Oblique Attempt) has the potential and more than adequate to meet the needs of the STEM students if they cannot cope up directly with their lessons about this area in Trigonometry.

Many pieces of research affirm the results of this outcome. Escoreal (2012) emphasized that through the use of Strategic Intervention Material (SIM), it reduced the number of least mastered skills of the students most especially if the SIM is content-centered and has real-life applications. Gultiano (2012) posited that with the aid of the SIM, students were enhanced for they became more attached to the material as it caught their attention with its color and the made-easy way of presenting the activities.

Table 6 presents the summary of the validation of the content and student validators of the two SIMs, which are SIM No. 1 (The Right Try) and SIM No. 2 (The Oblique Attempt). As displayed in the table, it shows that the content-validators validated the two materials with a grand mean of 4.75 , descriptively interpreted as excellent and the student-validators rated the two learning materials with a grand mean of 4.59 interpreted as more than adequate. This means that the developed intervention materials have great potential in helping developing learners.

The result is supported by the study of Hirsch (2001) which contended that the traditional instruction of teaching Trigonometry could no longer accommodate the learning needs of the 21st-century learners and further argued that we need to move away from traditional instruction by implementing the intervention programs and conceptual understanding. Due to the demand of the learners of this generation, educators became more creative to accommodate the new thinkers and discoverers. $21^{\text {st }}$-century learners are very demanding in terms of the instruction and curriculum that have been applied to them.

Table 6. Summary of Content and Student Validators' Validation of SIMs

\begin{tabular}{cccccc}
\hline $\begin{array}{c}\text { SIM } \\
\text { No. }\end{array}$ & Title & $\begin{array}{c}\text { Content- } \\
\text { Validators }\end{array}$ & Interpretation & $\begin{array}{c}\text { Student- } \\
\text { Validators }\end{array}$ & Interpretation \\
\hline 1 & The Right Try & 4.75 & Excellent & 4.58 & More Than Adequate \\
2 & The Oblique Attempt & 4.75 & Excellent & 4.60 & More Than Adequate \\
& Grand Mean & $\mathbf{4 . 7 5}$ & Excellent & $\mathbf{4 . 5 9}$ & More Than Adequate \\
\hline
\end{tabular}

Construction of the New SIM based on the Validation Results

Table 7.Blueprint of the newly-developed Strategic Intervention Material (SIM)

\begin{tabular}{clcc}
\hline Quarter & \multicolumn{1}{c}{ Competency } & Topic & Title \\
\hline & $\begin{array}{l}\text { Illustrate the unit circle and the relationship } \\
\text { between the linear and angular measures of a } \\
\text { central angle in a unit circle. }\end{array}$ & $\begin{array}{c}\text { Angles in a Unit } \\
\text { Circle }\end{array}$ & $\begin{array}{c}\text { The Ultimate } \\
\text { Shot }\end{array}$ \\
\hline
\end{tabular}

Table 8 presents the validation of the content-validators of the newly-developed SIM (The Ultimate Shot). As displayed in the table, it shows that design of the SIM, readability, importance of the content, appropriateness of activities, and ease of task completion surmount among the eight criteria with a mean of 5.00, descriptively interpreted as excellent and appropriateness of activities, ease of task completion, and clarity of directions used, opportunities for active learning, and 
usefulness of the SIM have the lowest mean of 4.80, but still interpreted as excellent. All of the criteria have the highest rating manifesting the overall mean response of 4.93 and interpreted as excellent. This only showed that the newlydeveloped SIM (The Ultimate Shot) has a higher suitability level in meeting the needs of the STEM students if they can experience difficulty in their lessons about this area in Trigonometry.

Various researches support this finding. Togonon (2011) stipulated that most often learners should find the concepts in Mathematics exciting particularly if the intervention materials are well-designed. This could also prove that learning occurs when there will be a new face of the materials being used in the classroom.

Table 8.Content-validators' Validation of the newly-developed SIM (The Ultimate Shot)

\begin{tabular}{lllc}
\hline & \multicolumn{1}{c}{ Criteria } & Mean & Interpretation \\
\hline 1. & Design of the SIM & 5.00 & Excellent \\
2. & Clarity of directions used & 4.80 & Excellent \\
3. & Readability & 5.00 & Excellent \\
4. Importance of the content & 5.00 & Excellent \\
5. Appropriateness of activities & 5.00 & Excellent \\
6. & Ease of task completion & 5.00 & Excellent \\
7. Opportunities for active learning & 4.80 & Excellent \\
8. Usefulness of the SIM in meeting & 4.80 & Excellent \\
& the needs of the learner & & \\
& Overall Mean & $\mathbf{4 . 9 3}$ & Excellent \\
\hline
\end{tabular}

Table 9. Student-validators' Validation of the newly-developed SIM (The Ultimate Shot)

\begin{tabular}{llcl}
\hline & \multicolumn{1}{c}{ Criteria } & Mean & Interpretation \\
\hline 1. & Design of the SIM & 5.00 & More Than Adequate \\
2. & Clarity of directions used & 5.00 & More Than Adequate \\
3. & Readability & 4.80 & More Than Adequate \\
4. Importance of the content & 5.00 & More Than Adequate \\
5. & Appropriateness of activities & 4.80 & More Than Adequate \\
6. Ease of task completion & 5.00 & More Than Adequate \\
7. & Opportunities for active learning & 5.00 & More Than Adequate \\
8. Usefulness of the SIM in meeting & 5.00 & More Than Adequate \\
& $\quad$ your needs as a learner & & \\
& $\quad$ Overall Mean & $\mathbf{4 . 9 5}$ & More Than Adequate \\
\hline
\end{tabular}

Table 9 presents the validation of the student-validators of the newly-developed SIM (The Ultimate Shot). As exhibited in the table, it shows that design of the SIM, clarity of directions used, importance of the content, ease of task completion, opportunities for active learning, and usefulness of the SIM dominate among the eight criteria with a mean of 5.00, descriptively interpreted as more than adequate and readability and appropriateness of activities have the lowest mean of 4.80, still interpreted as more than adequate. All of the criteria have the highest rating manifesting the overall mean response of 4.95 and interpreted as more than adequate. This only showed that the newly-developed SIM (The Ultimate Shot) has the potential and more than adequate to meet the needs of the STEM students if they cannot cope up directly with their lessons about this area in Trigonometry.

Few kinds of research confirm the results. Lagata (2012) emphasized that through the use of Strategic Intervention Material (SIM), the learners will become more knowledgeable in identifying errors able to determine cause and effect relationships. The study of Lagata about the causal model proved that learning is the result of the diverse instructional materials being applied in the classroom. 


\section{Descriptive Analysis}

There has been a pattern in the preferences of the content and student validators in terms of the eight criteria mentioned above in validating the two Strategic Intervention Materials (SIMs).

The overall result of the validation of the content and student validators of the two SIMs, which are SIM No. 1 (The Right Try) and SIM No. 2 (The Oblique Attempt) was highly exceptional in terms of the capacity of the materials to enhance the developing STEM learners in the field of Trigonometry.

It shows that the content-validators validated the two materials with a grand mean of 4.75 , descriptively interpreted as excellent and the student-validators rated the two learning materials with a grand mean of 4.59 interpreted as more than adequate. This means that the developed intervention materials have great potential in helping the developing learners and have a higher suitability level in meeting the needs of the STEM students if they can experience difficulty in their lessons about this area in Trigonometry.

It was found out that Strategic Intervention Materials (SIMs) are valid learning materials in helping the STEM learners who are not able to master yet a specific learning competency. In the guide card, the content-validators suggested that this card must stimulate more the interest of the learners in the topic, cites briefly the activities, and should be built on prior learning and prerequisite skills. The student-validators commented that the card should provide well-organized steps on the process of solving problems and mention the concrete outcome for them to be excited and motivated in arriving with a correct answer.

In the activity, card, the content-validators stipulated that this card should provide activities that are organized based on the focus skills being set and should construct clear and simple directions to maintain their momentum in finishing the entire material. This should allow students to make and create their techniques in getting the right solutions to a problem. The student-validators elaborated that this card should be learner-friendly and can accommodate those learners that find Mathematics difficult. This card should also set an atmosphere that could attract diverse learners to have full interest in the lesson.

In the assessment card, the content-validators explained that this card should provide unique and not complicated exercises, drills, or activities that allow students to assess their understanding of what they have learned and correct errors, yet commended because the researcher put an Answer card at the last part of the SIM. The student-validators elucidated that this card should accomplish its purpose to enhance their critical thinking since the material is individualistic. It should also be at a considerable level of difficulty to give opportunities to the developing learners.

In the enrichment card, the content-validators explicated that this card must be interesting and should include problems with real-life applications. This card should also provide activities that reinforce the content of the lesson and able to apply what they have learned into new contexts. The student-validators recommended that this card should also provide problems that can be solved collaboratively so that learners could explore more ways to get the correct answer.

In the reference card, both the content and student validators suggested that this card should also include online sources since today's learners are into technology already.

As to content- validators, in general, the developed Strategic Intervention Materials (SIMs) qualified to be teacher support materials that could help in enhancing STEM learners and considered to be good materials in providing intervention to the developing learners. As such, the layout of the SIM was commendable and content-wise but only suggested that the materials should follow strictly on the scope and sequence of topics in the $\mathrm{K}$ to 12 Mathematics curriculum. They also recommended of having clear instruction on the activities of SIM No. 2 and the words to be used should be suited to the reading comprehension level of the students since these materials are to those who are developing learners.

Furthermore, the two SIMs being made by the researcher are a one-step process in promoting quality learning towards all learners, hence minor revisions must be accomplished to fully apply the material immediately to the concerned students. Overall, the two SIMs are well-constructed. 
As to student- validators, overall, the two SIMs are considered to be good learner-enhancer materials. As to the design and content, they found out that the two SIMs can achieve their goals toward mastering the given learning competency. They stressed out that the contents are readable, understandable, and learner-friendly. It was recommended that there should be an improvement on the sequence of explaining the steps in solving a specific problem. It was mentioned that SIMs are very helpful tools to learners and suggested that the subtopics should be by volume so that it will be ready to take on the challenge of helping them, as learners.

\section{Conclusion and Recommendations}

Once the curriculum shifts, one of the controversies that will be observed by the implementers particularly the teachers is the scarcity of instructional materials because the change of the curriculum means a change of the teacher-support-materials too especially if the former curriculum is far different than the new one. The implementation of the $\mathrm{K}$ to 12 Basic Education Curriculum has brought lots of challenges to the Philippine educational system especially in the Senior High School where subjects are highly complex. The lack of instructional materials tops the list of challenges. To help the curriculum implementers on these prevalent problems, the researcher was able to develop Strategic Intervention Materials (SIMs) to aid those learners who were not able to master a specific learning competency.

This study showed that SIMs provide hope for the STEM students who generally have a bad impression of Trigonometry since it came out that they were able to rate the materials as more than adequate to meet their needs in coping with their difficulties towards that field in Mathematics. Aside from that, most of the students who validated the material have been attracted to the distinct design and clear instructions of the learning materials and most of them found the tasks contained in the SIM not that difficult to accomplish. The validation of the content-validators also proved the aforementioned observation of the students.

Based on the findings of the study, the Strategic Intervention Materials (SIMs) made by the researcher are considered by the content and student validators as suitable and appropriate for the STEM students for them to become competent in PreCalculus and master the learning competencies in Trigonometry. The SIMs are recommended to be used as teacher-support tools and learner-aid materials to ease the difficulties of developing learners and researchers should conduct similar studies on the use of Strategic Intervention Materials (SIMs) in other discipline to confirm the results of the study.

\section{References}

[1] Bryant, D. P. (2006). Instructional Design in Mathematics for Students with Learning Exceptionalities. Journal of Learning Disabilities, 30, 130-141.

[2] Bunagan, F. (2012). Development of Strategic Intervention Materials and Individualized Self-Instructional Modules on Selected Topics in Basic Mathematics. Journal of Research, (1).

[3] Calderon, J. (2012). Authentic assessment toolbox. Retrieved from http://jfmueller.faculty.noctrl. edu/toolbox/tasks.htm

[4] Cooper G. (2005). The effects of schema acquisition and rule automation on mathematical problem-solving transfer. Journal of Educational Psychology, 79, 347-362.

[5] Dacumos, L. (2015). Personality styles, stress-coping mechanisms, and academic performance of grade nine students in science. Manuscript submitted for publication.

[6] Dahar, M. (2011). Effect on the Availability and the Use of Strategic Intervention Material on Academic Performance of Students in Punuab (Pakistan), Eurojournal Publishing Inc., 345-347.

[7] Drucker, K. (2006). On problem-solving. Psychological Monographs. Cognitive, metacognitive, and motivational aspects of problemsolving in trigonometry. 58.

[8] Escoreal, A. (2012). Strategic Intervention Material: A Tool to Reduce Least Learned Skills in Grade 10 Mathematics. Outcome and Process, 45-79.

[9] Gultiano, A. (2012). Effects of strategic intervention material (SIM) on the academic achievements in Chemistry of public high school students. Retrieved from http://www.slideshare. net/neoyen/strategic-intervention-material.

[10] Gur, H. ( 2009 ) Trigonometry Learning. New Horizons in Education, 57(1), 67- 80.

[11] Hirsch, C. (2001). Trigonometry today. Mathematics Teacher, 84(2), 98-106.

[12] Javier, C. (2013). Preservice Secondary School Mathematics Teachers' Knowledge of Trigonometry: Subject Matter Content Knowledge, Pedagogical Content Knowledge and Envisioned Pedagogy. Unpublished Ph.D. Thesis, University of lowa: USA.

[13] Lagata, G. A. (2012). Instructional leadership and school achievement: Validation of a causal model. Educational Administration Quarterly, 26, 94-125.

[14] Lewis, J. (2013). Using active learning instructional strategies to create excitement and enhance learning. Retrieved from https://www. cte.cornell.edu/documents/presentations/ Eisen-Handout.pdf

[15] Olawale, S. (2013). The use of instructional materials for effective learning of Islamic studies. International Journal of Jihat al-Islam, $6,(2)$. 
[16] Orhun, N. (2002) The effects of learning styles on high school students" achievement on a mathematics course. Educational Research and Reviews, 8(14), 1158-1165.

[17] Saclao, J. (2015). Development and Impact of SIM-MOD (Strategic Intervention Material and Module Combined) on Students' Academic Achievement in Mathematics at the $8^{\text {th }}$ Grade Level. 13th National Convention on Statistics (NCS).Journal of Science and Mathematics, 6(90 190-212).

[18] Seels, B.B., \& Richey, R.C. (1994). Instructional Technology: The definition and domains of the field. Washington, D.C: Association for Educational Communications and Technology.

[19] Togonon, I. (2011). Development and Evaluation of Project-Based SIM-MOD (PB-SIM) in Teaching High School Chemistry. Technological University of the Philippines.

[20] Vygotsky, L. (1978). Interaction between learning and development, mind, and society. Cambridge, MA. Harvard University Press.

[21] Weselby, C. (2014). What is differentiated instruction? Examples of how to differentiate instruction in the classroom. Retrieved from http://education.cu-portland.edu/blog/teaching-strategies/examples-of-differentiated-instruction/ 